Thorax 1987;42:549-550

\title{
Repair of incisional hernia after median sternotomy
}

\author{
B R DAVIDSON, J S BAILEY \\ From the Department of Cardiothoracic Surgery, Groby Road Hospital, Leicester
}

\begin{abstract}
About 19000 cardiac surgical procedures are carried out annually in the United Kingdom, $\mathbf{4 0 0 0}$ being for congenital defects (UK Cardiac Surgical Register: Society of Thoracic and Cardiovacular Surgeons of Great Britain and Ireland, 1983). Most of these procedures use the median sternotomy incision for access to the heart and great vessels. Epigastric incisional hernias may occur as a complication in up to $4 \%$ of these operations. ${ }^{1}$ The defects occur in the subxiphoid position, where the incision enters the epigastrium. In a review of 582 consecutive median sternotomy wounds 20 incisional hernias were found. Forty per cent were symptomatic, the main complaint being of epigastric pain and discomfort exacerbated by movement. Small defects were satisfactorily repaired by standard techniques, such as a nylon darn or Mayo repair. ${ }^{2}$ Large subxiphoid defects can be successfully repaired by a modification of the Wells procedure. $^{3}$
\end{abstract}

\section{Patients and methods}

From June 1977 to June 1985582 median sternotomies were carried out at Groby Road Hospital by a single surgical firm in patients over 16 years of age. Review of these patients showed that 20 patients had developed incisional epigastric hernias postoperatively. Eight patients had symptoms and had a repair carried out. These hernias consisted of five small defects $(<4 \mathrm{~cm}$ diameter), and direct closure of the defect with non-absorbable sutures produced satisfactory results (one Mayo repair, two nylon darns, one Keel repair, ${ }^{4}$ and one Ethiflex double layer repair). Three patients had large subxiphoid defects $(>10 \mathrm{~cm})$, repaired by a modification of the Wells procedure, ${ }^{3}$ which involves overlapping of the mobilised anterior rectus sheath. No complications accompanied the flap repairs and a satisfactory result was produced in all three. Follow up for eight months, two years six months, and three years seven months has shown no sign of recurrence.

Technique of double door flap applied to subxiphoid defects The margins of the hernial sac are defined and an ellipse of skin that includes the previous scar is excised from above the xiphoid process to the lower margin of the sac, adequate to

Address for reprint requests: Mr B R Davidson, FRCS, 2 Sarson Street, Quorn, Loughborough, Leicestershire LE128EA.

Accepted 28 January 1987 avoid a redundant skin flap on reduction of the hernial sac. Skin flaps are mobilised from the hernial sac and laterally from the rectus sheath. Superiorly the xiphoid process and external oblique aponeurosis overlying the lower costal cartilages is exposed, as is the anterior rectus sheath for $2-3 \mathrm{~cm}$ below the defect. The hernial sac is reduced and the margins are cleared for 1-2 cm from the posterior sheath. Flaps based on the linea alba are reflected medially from the anterior rectus sheath on left and right, and are of sufficient size to close the defect without tension. The free edge of the flap is sutured to the opposite edge of the defect with a continuous non-absorbable suture, any excess flap being trimmed. The procedure is carried out first with one side (figure A) and then the other (B), producing a sound two layered repair (C). Suction drains are inserted through seperate stab incisions to lie between the skin flaps and the anterior rectus sheath and the skin flaps sutured with interrupted nylon matress sutures.

\section{Discussion}

This technique was originally described by Wells ${ }^{3}$ in 1956 for the repair of epigastric incisional hernia following surgery on the upper gastrointestinal tract. In 1963 Arner et $a l^{5}$ carried out double door reconstruction on 30 patients with incisional epigastric hernias who had a defect of $11-17 \mathrm{~cm}$. All patients had a satisfactory result with no recurrences in a one to four year follow up. The recurrence rate after standard repair techniques may be as high as $44 \% .^{6}$ Many techniques, such as the "Keel" repair, ${ }^{4}$ have not yet had an adequate length of follow up. Carrying out lateral relieving incisions in the anterior sheath has been shown to produce satisfactory results with low recurrence rates. ${ }^{7}$ An alternative to mobilisation or utilisation of the rectus sheath for repair of incisional epigastric defects is the implantation of synthetic materials in the form of meshes. Tantalum gauze was utilised in the 1950 s because of its inert nature. The long term results were poor. ${ }^{8}$ Pliable synthetic meshes, however, produce good long term results with few infective complications. ${ }^{9}$ Factors that appear to be important in the prevention of incisional hernias are the use of non-absorbable sutures, weight reduction in obese patients, and the avoidance of reoperation. ${ }^{1}$

Our thanks go to Miss Jane Middleton, surgical secretary, for assistance in the preparation of this paper. 

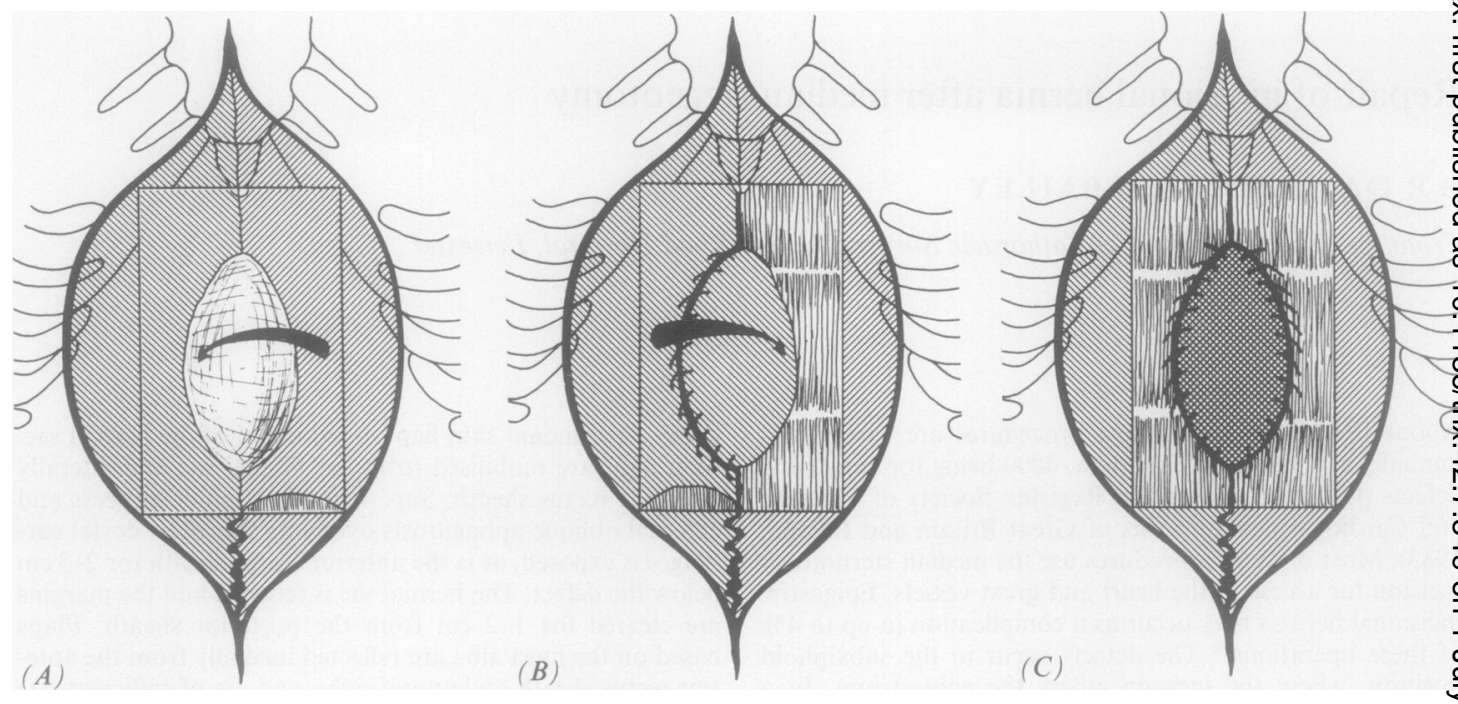

Repair of epigastric incisional hernia by a modification of the Wells procedure. (A) Skin flaps are mobilised to extend to abovi the xiphoid process and 1-2 cm below the defect (incisions in the external oblique aponeurosis and anterior rectus sheath illustrated). The left flap is mobilised and sutured to the right margin of the defect. (B) The right flap is then mobilised and sutured to the left margin of the defect. (C) A double layered repair is produced.

\section{References}

1 Davidson BR, Bailey JS. Incisional herniae following median sternotomy incisions. Their incidence and aetiology. Br J Surg 1986;73:995-6.

2 Mayo WJ. Further experience with the ventral overlapping operation for the radical cure of umbilical hernia. JAMA 1903;41:225-6.

3 Wells CA. Hernia: incisional and umbilical. Ann $R$ Coll Surg 1956;19:316-8.

4 Maingot R. The "Keel" operation for large ventral hernia. Med Press 1954;232:134-8.
5 Arner O, Eriksson F, Sundblad R. Double door reconstructioß for epigastric incisional herniae. Acta Chir Scand 1963;sup

6 Horton RE, Smith PC. Incisional hernia. Proc $R$ Soc Mege 1969;62:513-4.

7 Young D. Repair of epigastric incisional hernia. Br J Surg 1961;48:514-6.

8 Koontz AR. Failures with Tantalum gauze in ventral hernia repair. Arch Surg 1955;70:123-7.

9 Adler RH, Firme CN. Use of pliable synthetic mesh in the repay of hernias and tissue defects. Surg Gynecol Obstef 1959;108:199-206. 